\title{
Figure Correction: The Effect of a Cellular-Enabled Glucose Meter on Glucose Control for Patients With Diabetes: Prospective Pre-Post Study
}

Jennifer B Bollyky ${ }^{1}$, MD; Stephanie T Melton ${ }^{2}, \mathrm{MA}, \mathrm{PhD}$; Tong Xu ${ }^{3}$, MSc; Stefanie L Painter ${ }^{3}$, DHEd; Brian Knox ${ }^{2}$, MD

${ }^{1}$ Stanford University School of Medicine, Stanford, CA, United States

${ }^{2}$ University of South Florida, Florida, CA, United States

${ }^{3}$ Livongo Health, Mountain View, CA, United States

\section{Corresponding Author:}

Tong Xu, MSc

Livongo Health

150 W Evelyn Ave \#150

Mountain View, CA, 94041

United States

Phone: 16265597154

Email: kxu@livongo.com

\section{Related Article:}

Correction of: https://diabetes.jmir.org/2019/4/e14799/

(JMIR Diabetes 2020;5(3):e21993) doi: 10.2196/21993

In "The Effect of a Cellular-Enabled Glucose Meter on Glucose Control for Patients With Diabetes: Prospective Pre-Post Study" (JMIR Diabetes 2019;4(4):e14799), the authors noted an error in the caption of Figure 6.

The caption formerly said:

Change in hemoglobin $A_{1 c}\left(H b A_{1 c}\right)$ from baseline by timepoint for type 2 diabetes with insulin use.
Change in hemoglobin $A_{1 c}\left(H B A_{1 c}\right)$ from baseline by timepoint for all participants with insulin use.

The correction will appear in the online version of the paper on the JMIR Publications website on July 28, together with the publication of this correction notice. Because this was made after submission to PubMed, PubMed Central, and other full-text repositories, the corrected article has also been resubmitted to those repositories.

This has been revised to:

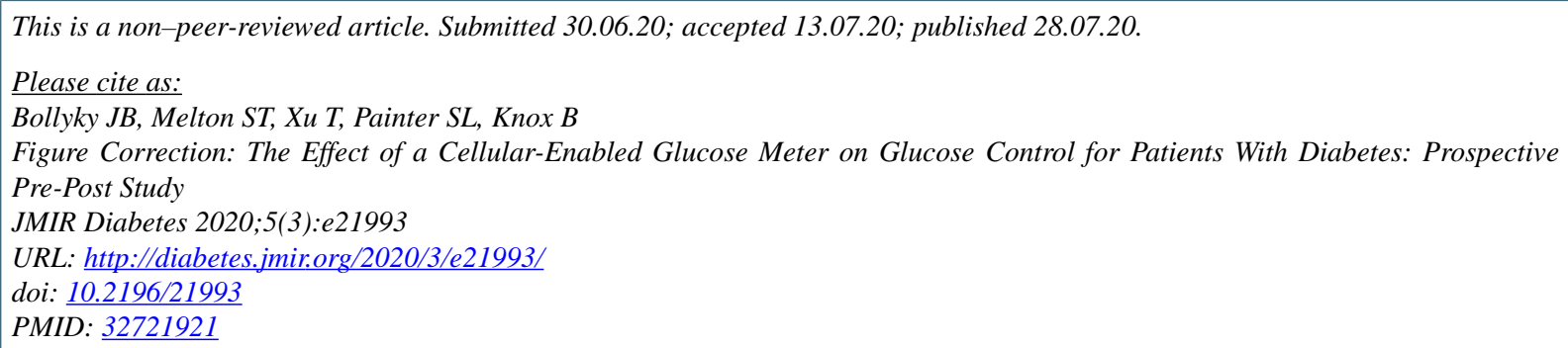

CJennifer B Bollyky, Stephanie T Melton, Tong Xu, Stefanie L Painter, Brian Knox. Originally published in JMIR Diabetes (http://diabetes.jmir.org), 28.07.2020. This is an open-access article distributed under the terms of the Creative Commons Attribution License (https://creativecommons.org/licenses/by/4.0/), which permits unrestricted use, distribution, and reproduction in any medium, provided the original work, first published in JMIR Diabetes, is properly cited. The complete bibliographic information, a link to the original publication on http://diabetes.jmir.org/, as well as this copyright and license information must be included. 